\title{
Phytase production by Aspergillus niger NCIM 563 for a novel application to degrade organophosphorus pesticides
}

\author{
Parin C. Shah ${ }^{1,2}$, V. Ravi Kumar ${ }^{1,3}$, Syed G. Dastager ${ }^{1,2}$ and Jayant M. Khire ${ }^{1,2^{*}}$
}

\begin{abstract}
The production of phytase using Aspergillus niger NCIM 563 under submerged fermentation conditions was studied using protein rich chickpea flour as substrate. Employing a hybrid statistical media optimization strategy of Plackett-Burman and Box-Behnken experimental designs in shake-flasks gave an increased phytase activity from an initial $66 \mathrm{IU} / \mathrm{mL}$ in $216 \mathrm{~h}$ to $160 \mathrm{IU} / \mathrm{mL}$ in a reduced time of $132 \mathrm{~h}$. Productivity, thus increased by 3.97 times from 7.3 to $29 \mathrm{IU} / \mathrm{mL} /$ day. Using the optimized media, the production was successfully scaled-up further and improved up to $164 \mathrm{IU} / \mathrm{mL}$ in $96 \mathrm{~h}$ by studies carried out employing 2 and 10-L fermenters. The enzyme supernatant was recovered using centrifugal separation of biomass and the stability of the produced phytase was tested for animal feed applications under gastric conditions. In vitro degradation studies of water soluble monocrotophos, methyl parathion and water insoluble chlorpyrifos, pesticides used extensively in agriculture was carried out. It was observed by HPLC analysis that phytase could degrade $72 \%$ of chlorpyrifos at $\mathrm{pH} 7.0,35^{\circ} \mathrm{C}$. Comparable results were obtained with monocrotophos and methyl parathion. With chlorpyrifos at higher temperature $50{ }^{\circ} \mathrm{C}$ as much as $91 \%$ degradation could be obtained. The degradation of chlorpyrifos was further validated by spraying phytase on harvested green chilli (Capsicum annuum $\mathrm{L}$ ) under normal conditions of $\mathrm{pH} 7.0,35^{\circ} \mathrm{C}$ and the degradation products obtained analyzed by LCMS. Thus, the present study brings out a potentially novel application of phytase for biodegradation of organophosphorus pesticides.
\end{abstract}

Keywords: Aspergillus niger, Green chickpea flour, Fermenter scale, Organophosphorus pesticide, Phytase, Submerged fermentation

\section{Introduction}

Over the past century, an increase in demand of food grains and vegetables has led to an extensive use of manmade pesticides in agriculture. In fact, crop protection in India is known to annually use nearly 40,000 metric tons of pesticides. Organophosphorus pesticides (OpP), are widely used in agriculture for controlling variety of sucking, chewing and boring insects, spider mites, aphides and pests. In particular, OpP cannot be easily removed by washing and rinsing with tap water (Vendan 2016) and this leads to bioaccumulation in the food chain.

\footnotetext{
*Correspondence: khirejayant@gmail.com

${ }^{2}$ National Collection of Industrial Micro-organisms (NCIM) Resource Center, Biochemical Sciences Division, CSIR-NCL, Pune 411008, India Full list of author information is available at the end of the article
}

Organophosphorus pesticides are esters of phosphoric acid, which include aliphatic, phenyl and heterocyclic derivatives (Baishya and Sarma 2015), which are known to be potent irreversible acetylcholinesterase (AChE) inhibitors by phosphorylation of the serine residue at the enzyme active site. This leads to adverse effects on the nervous system of exposed animals including humans (Mileson et al. 1998), and there exists a dire need to degrade OpP post-harvest, so as to prevent their entry into the food chain.

The currently used physicochemical processes for OpP remediation include incineration or disposal in landfills that are expensive, non-ecofriendly and the process is often incomplete leading to formation of toxic intermediates (Debarati et al. 2005). Alternatively, the use of wholecell microorganisms is advantageous because it offers a 
safe, economic and eco-friendly green option (Rayu et al. 2012; Sutherland et al. 2004). The factors that impact bioremediation are mainly the availability of organic sources for microbial growth, optimal $\mathrm{pH}$, bioavailability of inhibitory substrates and the satisfaction of regulatory norms for release of microbes into the environment (Boopathy 2000), which can be addressed by using cellfree microbial enzymes that can act on diverse pollutants (Scott et al. 2011).

Most widely studied cell-free enzymes for OpP degradation are from bacteria, viz., organophosphorus hydrolase (EC 8.1.3.1) (Gao et al. 2012), phosphotriesterase (EC 3.1.8.1) (Chino-Flores et al. 2012) and organophosphorus acid hydrolase (EC 3.1.8.1) (Theriot and Grunden 2011). There are few reports where, fungi have been studied for OpP degradation by cleaving the phosphate group (John and Shaike 2015; Wyss et al. 1999). Phytase (PYT) or myo-inositol hexakisphosphate phosphohydrolase (EC 3.1.3.8) from Aspergillus niger NCIM 563, is a good example of a hydrolytic enzyme that can release inorganic phosphorus by the degradation of phytic acid (Bhavsar et al. 2008). Current progress on PYT research is focused on phytic acid degradation for major animal feed supplementation, plant growth promotion and human nutrition (Dersjant-Li et al. 2015; Kumar et al. 2010). The GRAS cleared PYT enzyme has not been studied for its potential for biodegradation of toxic pesticides by phosphorous release and is therefore studied here. A positive result would bring out a novel and useful enzymatic application of PYT for pesticide detoxification.

Agricultural residues including rice bran, wheat bran, groundnut oil cake, corn starch, etc., are widely used as substrates for PYT production (Bhavsar et al. 2008; Alves et al. 2016; Buddhiwant et al. 2015). However, the cost of production increases with use of agricultural residue as it needs pre-treatment (Bhavsar et al. 2008; Rani et al. 2014). The need for cost effective sustainable production requires alternative substrate for PYT production. In this context, the use of protein-rich legume flour as substrate has advantages for sustainable low cost PYT production because it can avoid the pre-treatment step. India is the largest producers of chickpea (Cicer arietinum) (7.17 metric tons in 2014-2015) but around $20 \%$ of the cultivated chickpea seeds are rejected due to non-uniform growth, color and damage during harvesting and post-harvesting process (Torres-Fuentes et al. 2011). These rejected green seeds are however, rich in protein, carbohydrate, lipids and major dietary minerals such as calcium, phosphorus, magnesium, iron and potassium (Christodoulou et al. 2006) and has been used in poultry diet (Garsen et al. 2007). For the above reasons, in the present study, in view of its availability as agricultural waste, we used green chickpea flour (GrCf) as the substrate of choice for producing and maximizing PYT production. The increased production of PYT would facilitate studying for animal feed applications and as discussed earlier in conducting studies related to dephosphorylation potential of $\mathrm{OpP}$ by this extracellular enzyme.

In the present study for increasing the production of extracellular PYT from GrCf using A. niger, growth media optimization was envisaged using shake flasks under submerged fermentation condition $(\mathrm{SmF})$ by employing an effective hybrid strategy that involves carrying out statistical sets of experiments (Shah et al. 2009). In this approach, we initially aim at identifying the significant factors influencing PYT production by implementing a Plackett-Burman Design (PBD) of experiments (Plackett and Burman 1956). Subsequently, a second set of experiments can then be conducted to further optimize the levels of the significant factors that maximize PYT production by application of a more rigorous experimental design such as the Box Behnken design (BBD) (Box et al. 1978; Khuri and Cornell 1987). Obtaining positive results would then suggest scale-up studies with 2 and 10-L fermenters so as to confirm maintenance or obtain improvements in the production levels for process feasibility. This would also require assessing the suitability and stability of the PYT produced by GrCf so that animal feed applications can become possible. As discussed above, from a novel application point of view, it would be interesting to study and test the enzyme effectiveness for in vitro pesticide degradation using for example a commercially available OpP such as water insoluble chlorpyrifos (CPyF) (Dursban 2E@) and water soluble monocrotophos (MCP) and methyl parathion (MP). Again, a positive result would suggest carrying out studies with a test system such as post-harvest fresh green chillies (Capsicum annum L) treated with CPyF. The results obtained by carrying out suitable studies for the above objectives and plan are discussed in this work.

\section{Materials and methods \\ Chemicals}

Phytic acid sodium salt, 3, 5, 6-trichloro-2-pyridinol (TCP) and diethyl thiophosphate (DETP) was purchased from Sigma Chemical Company (St. Louis, MO, USA). Acetonitrile (ACN) of HPLC grade was purchased from Merck. All other chemicals used were of analytical grade. CPyF (Dursban 2E®, 20\%), MCP (36\%) and MP (50\%), harvested green chilli, soybean meal and seeds of green chickpea were purchased from a local market. The seeds were minced in a grinder to obtain green chickpea flour (GrCf). 


\section{Microorganism and production in basal media}

Aspergillus niger NCIM 563, used in the present study was obtained from National Collection of Industrial Microorganisms (NCIM), CSIR-National Chemical Laboratory (CSIR-NCL), Pune, India, which was maintained on potato dextrose agar (PDA) slants and stored at $4{ }^{\circ} \mathrm{C}$. A time course of the PYT production was studied using the basal media ( $\mathrm{pH}$ 5.5) in triplicates. $100 \mathrm{~mL}$ media comprising of (g\%): $1.0 \mathrm{GrCf} ; 5.0$ glucose; 0.86 $\mathrm{NaNO}_{3} ; 0.05 \mathrm{KCl} ; 0.05 \mathrm{MgSO}_{4} \cdot 7 \mathrm{H}_{2} \mathrm{O} ; 0.01 \mathrm{FeSO}_{4} \cdot 7 \mathrm{H}_{2} \mathrm{O}$ was dispensed in $250 \mathrm{~mL}$ Erlenmeyer flask and sterilized by autoclaving at $121{ }^{\circ} \mathrm{C}$ for $20 \mathrm{~min}$. Spores from 7 days old PDA slant were gently scraped using sterile wire loop with $25 \mathrm{~mL}$ sterile saline solution containing $0.01 \%$ Tween 80 . The spore suspension was collected in sterile tube and homogenized by vortexing for $1 \mathrm{~min}$. $1 \times 10^{7}$ spores (using Neubaur chamber) was used as spore inoculum (Sp-I) for inoculating the basal media and incubated at $28{ }^{\circ} \mathrm{C}$ at $170 \mathrm{rpm}$ under aerated culture conditions. Vegetative inoculum (Ve-I) was prepared by inoculating $5 \mathrm{~mL}$ basal media with $1 \times 10^{7}$ spores under same aerated culture conditions for $10 \mathrm{~h}$ which was used for inoculating $95 \mathrm{~mL}$ basal media. The samples were withdrawn every $24 \mathrm{~h}$ and centrifuged. The supernatant was checked for total residual glucose and PYT activity.

\section{PYT assay}

The PYT analysis solution consisting of $3 \mathrm{mM}$ sodium phytate with $100 \mathrm{mM}$ glycine- $\mathrm{HCl}$ buffer (pH 2.5) and $100 \mu \mathrm{L}$ of liquid enzyme extract solution was incubated for $30 \mathrm{~min}$ at $50{ }^{\circ} \mathrm{C}$. The liberated inorganic phosphate was measured by the ammonium molybdate method (Heinohen and Lathi 1981). A freshly prepared solution of acetone, $5 \mathrm{~N} \mathrm{H}_{2} \mathrm{SO}_{4}, 10 \mathrm{mM}$ ammonium molybdate $(2: 1: 1, \mathrm{v} / \mathrm{v})$ and $400 \mu \mathrm{L}$ citric acid $(1 \mathrm{M})$ was added to the enzyme-substrate solution and absorbance was measured at $370 \mathrm{~nm}$ against blank consisting of buffer and substrate. One unit of PYT activity (IU) was expressed as the amount of enzyme that liberates $1 \mu \mathrm{mol}$ phosphorus/ $\mathrm{min} / \mathrm{mL}$ under standard assay conditions while enzyme production was expressed as PYT activity IU $/ \mathrm{mL}$.

\section{Stability studies}

The influence of $\mathrm{pH}$ and temperature on PYT activity was determined by assaying in the $\mathrm{pH}$ range of 1.5 and 9.0 using $100 \mathrm{mM}$ buffers: glycine- $\mathrm{HCl}(\mathrm{pH} 2.0-3.0)$, sodium acetate ( $\mathrm{pH} 4.0-6.0)$, Tris- $\mathrm{HCl}(\mathrm{pH} 7.0-8.0)$, and glycine$\mathrm{NaOH}(\mathrm{pH} 9.0)$ at $50{ }^{\circ} \mathrm{C}$. The $\mathrm{pH}$ stability using the same buffer solutions was also determined by pre-incubating enzyme samples at $35^{\circ} \mathrm{C}$ for the period of $12 \mathrm{~h}$ considering PYT activity at zero time as $100 \%$. The studies on optimum temperature were carried out in the temperature range of $30-70{ }^{\circ} \mathrm{C}$, while the temperature stability was determined by incubating the enzyme samples over the above temperature range for a period of $1 \mathrm{~h}$ on comparing with the control without incubation. The stability of PYT was also checked at gastric conditions of poultry. One gram soybean meal was dissolved in $9 \mathrm{~mL}$ of simulated gastric fluid $(250 \mathrm{mM}$ glycine- $\mathrm{HCl}$ containing $2.0 \mathrm{mg} / \mathrm{mL} \mathrm{NaCl}$ and $3.2 \mathrm{mg} / \mathrm{mL}$ of pepsin) and the $\mathrm{pH}$ was adjusted over a range from 1.5 to 6.5 using $\mathrm{HCl}$ and $\mathrm{NaOH}$ as required. The solutions were incubated at $37{ }^{\circ} \mathrm{C}$ for $30 \mathrm{~min}$, as the poultry gut temperature varies from $37-39{ }^{\circ} \mathrm{C}$ (Lei and Stahl 2001). $40 \mathrm{IU}$ of PYT was added to the solution and incubated at $37{ }^{\circ} \mathrm{C}$ for $60 \mathrm{~min}$. The released phosphorus was determined as described in PYT assay.

\section{Biodegradation of OpP using PYT}

The potential of extra-cellular PYT, produced in basal media, was studied for biodegradation of $\mathrm{CPyF}$, a water insoluble organophosphate. $1 \mathrm{~mL}$ stock solution of $\mathrm{CPyF}$ $(10,000 \mathrm{ppm})$ was incubated with $100 \mu \mathrm{L}$ mycelial free PYT (100 IU; specific activity $53 \mathrm{IU} / \mathrm{mg}$ ) for $2 \mathrm{~h}$ at $35^{\circ} \mathrm{C}, \mathrm{pH} 7$ as well as its optimum conditions $\left(50{ }^{\circ} \mathrm{C}, \mathrm{pH} 2.5\right)$. The selection of a high concentration of $\mathrm{CPyF}$ was employed for sensing and quantifying the degradation metabolites. The treated sample was diluted 10 times with mobile phase and the amount of residual CPyF was monitored using HPLC as mentioned in analytical methods. For other OpPs (MCP and MP), studies were carried out in similar way.

\section{Analytical methods}

Concentration of the protein $(\mathrm{mg})$ was determined using Lowry method with bovine serum albumin as standard (Lowry et al. 1951) and specific activity (IU/mg) using enzyme units and protein concentration were calculated. Di-nitro salicylic acid (DNSA) method (Miller 1959) was used to calculate total residual reducing sugar concentration.

The analysis of OpPs were carried out using HPLC (Dionex-ASI 100, auto sampler series) with reverse-phase column $(\mathrm{C} 18-4.6 \times 250 \mathrm{~mm}$, Waters $)$ maintained at $40{ }^{\circ} \mathrm{C}$. The mobile phase used was mixture of ACN: water $(70: 30 \mathrm{v} / \mathrm{v})$, with flow rate of $0.5 \mathrm{~mL} / \mathrm{min}$. The detection was done at $230 \mathrm{~nm}$ and injection volume was 50 $\mu \mathrm{L}$. Standard solutions of OpP was transferred in vials to reach final concentrations in range of $100-1000 \mathrm{ppm}$ using mobile phase. The analysis of $\mathrm{CPyF}$ and its degraded products on green chilly were carried out using LC-MS (Waters-Xevo TQD-USA) with reverse phase C18 column (Acquity-UTLC BEH-2.1 $\times 100 \mathrm{~mm}$ ) maintained at $45^{\circ} \mathrm{C}$. The mobile phase used was mixture of $\mathrm{ACN}$ : water $(70: 30 \mathrm{v} / \mathrm{v})$, with flow rate of $0.3 \mathrm{~mL} / \mathrm{min}$. Injection volume of sample was $5 \mu \mathrm{L}$. Standard solutions of each was transferred in vials to reach concentration in range of $0.2-1 \mathrm{ppm}$ using mobile phase. 


\section{Application of PYT on harvested green chilli (Capsicum annuum L)}

The potential of PYT to degrade CPyF on harvested green chilly was studied at $35{ }^{\circ} \mathrm{C}, \mathrm{pH}$ 7.0. Green chillies $(250 \mathrm{~g})$, obtained from local market was sprayed with CPyF (20 ppm) and dried. One part of the chillies (test) was treated with crude mycelial-free PYT (80 IU) at $35{ }^{\circ} \mathrm{C}$ and $\mathrm{pH} 7.0$ for $2 \mathrm{~h}$ keeping the second part untreated (control). Both the parts were separately cut into small pieces and homogenized with a household mill (equipped with stainless steel knives). $10 \mathrm{~mL}$ of ACN was added to $10 \pm 0.1 \mathrm{~g}$ sample and vortexed for $1 \mathrm{~min}$ to which $10 \mathrm{~g}$ sodium sulfate was added and homogenized at $15,000 \mathrm{rpm}$ for $1 \mathrm{~min}$. The samples were centrifuged at $5000 \mathrm{rpm}$ for $5 \mathrm{~min}$ and $5 \mathrm{~mL}$ of the supernatant were transferred to a $15 \mathrm{~mL}$ PTFE tube. $10 \mathrm{mg}$ graphitized carbon black and $25 \mathrm{mg}$ primary secondary amine were added to remove colored impurities. The extract was shaken using a vortex mixer for $30 \mathrm{~s}$ and centrifuged at $10,000 \mathrm{rpm}$ for $5 \mathrm{~min} .2 \mathrm{~mL}$ of the supernatant was used to analyze the presence of $\mathrm{CPyF}$ and its degraded metabolites using LC-MS as mentioned in analytical methods.

\section{Media optimization in shake flasks}

Carrying out a PBD of experiments offers a rapid multifactor way to screen and identify the most significant factors (Plackett and Burman 1956). The potential effect of 10 variables (Additional file 1: Table S1) on PYT production, were evaluated in 12 PBD runs at two levels, low level (-) and high level (+). The choice of the above variables was made based on reports available for enhanced PYT production by solid state fermentation (Bhavsar et al. 2013). The complete PBD matrix for screening was designed using a standard Plackett-Burman orthogonal array constructed using Design Expert Software (DES) Version 7.1.2, Stat-Ease, Minneapolis, MN, USA. The response values of PYT produced in $\mathrm{IU} / \mathrm{mL}$ were analyzed to obtain a best-fit linear mathematical model that could be further analyzed by ANOVA for acceptability. Subsequently, a BBD of experiments was generated by DES and studies at three different levels $-1,0,+1$ (Additional file 1: Table S2) were carried out to further optimize enzyme production levels with respect to the major factors identified by PBD. The less significant factors were maintained at the average of the high and low levels used in the PBD study. A best-fit model for enzyme production was further studied by ANOVA to test for its statistical significance.

\section{Fermenter scale production}

Scale-up studies in a batch fermenter (New Brunswick BioFlo 110) with 2-L media was carried out on the basis of optimized media formulation. Successive fermentation batches at different rpm (400, 500 and $600 \mathrm{rpm})$ were performed with constant aeration of $0.5 \mathrm{vvm}$ and temperature of $28{ }^{\circ} \mathrm{C}$. The fermenter containing 1.8-L medium that was earlier sterilized in situ was inoculated with $36 \mathrm{~h}$ old Ve-I (200 mL). The dissolved oxygen (DO) was measured using Mettler Toledo oxygen probe. Samples from the fermenter were withdrawn at regular intervals and analyzed for PYT activity and residual glucose on biomass separation. The process was further scaled up using a 10-L capacity fermenter with 1-L, 36 h old Ve-I.

\section{Results}

\section{PYT production in basal media}

The PYT production was tested using two types of inoculum; spore (Sp-I) and vegetative (Ve-I). The results showed, slow and gradual increase in PYT production using Sp-I, with the maximum activity of $66 \pm 3.3 \mathrm{IU} / \mathrm{mL}$ on 9th day, (i.e., 216 h) (Fig. 1). The glucose concentration also showed a gradual depletion, with complete utilization by 10th day (i.e., $240 \mathrm{~h}$ ). In fact, using Ve-I, higher PYT activity of $86 \pm 4.3 \mathrm{IU} / \mathrm{mL}$ was observed in a lower production time of 6 days (i.e., $144 \mathrm{~h}$ ) with glucose depletion in 7 days (i.e., $168 \mathrm{~h}$ ). Thus, the productivity [units of enzyme produced per day ( $\mathrm{IU} / \mathrm{mL} /$ day)] increased from 7.3 IU/mL/day obtained using Sp-I to $14.3 \mathrm{IU} / \mathrm{mL} /$ day using Ve-I. Thus, the type of inoculum has marked effect on the production of PYT and all further studies were therefore carried out using Ve-I.

\section{Stability studies of PYT}

The conditions for optimum activity and stability of the PYT was assessed by carrying out studies with respect to temperature and $\mathrm{pH}$. Optimum temperature studies ranged from 30 to $70{ }^{\circ} \mathrm{C}$. It was observed that, the optimum temperature for maximum PYT activity is $50{ }^{\circ} \mathrm{C}$

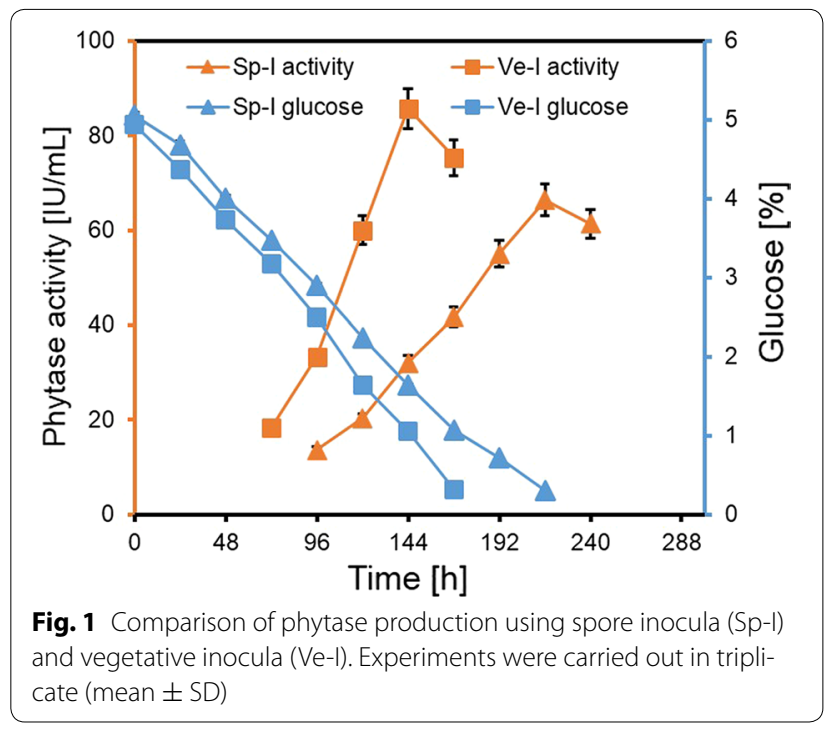


(Additional file 1: Figure S1). On considering the activity at $50{ }^{\circ} \mathrm{C}$ to be $100 \%$, we observe that at $35{ }^{\circ} \mathrm{C}$, the activity reduces to $30 \%$ of maximum activity and at $60{ }^{\circ} \mathrm{C}$ to $60 \%$ of maximum activity. Temperature stability studies were then carried out, which showed $100 \%$ stability in $1 \mathrm{~h}$ from 30 to $50{ }^{\circ} \mathrm{C}$ (Additional file 1: Figure S1) while $20 \%$ activity was reduced at $60{ }^{\circ} \mathrm{C}, 50 \%$ at $65{ }^{\circ} \mathrm{C}$ and $100 \%$ at $70{ }^{\circ} \mathrm{C}$. Studies with varying $\mathrm{pH}$ interestingly showed that the enzyme showed high activity at a low $\mathrm{pH}$ value of 2.5 (Additional file 1: Figure S2). Considering the activity at pH 2.5 to be $100 \%$, only 50 and $10 \%$ activity was observed at $\mathrm{pH} 4.5$ and 7.0, respectively. It may be noted that the PYT showed overall broad $\mathrm{pH}$ stability from $\mathrm{pH}$ 2.5-9 (Additional file 1: Figure S2). Experiments showed that the enzyme activity was retained for $12 \mathrm{~h}$ in the $\mathrm{pH}$ range studied. The $\mathrm{pH}$ and temperature stability profile was also determined under poultry gut conditions as described in methods. High efficacy of phosphate release was shown by the PYT in simulated gastric fluid in $\mathrm{pH}$ ranging from 2.0 to 4.5 (Additional file 1: Figure S3).

\section{Biodegradation of OpP using PYT}

The ability of crude PYT, (100 IU) produced using basal media, to degrade $\mathrm{CPyF}$ was studied both under normal conditions $\left(35{ }^{\circ} \mathrm{C}, \mathrm{pH} 7.0\right)$ as well as under optimum enzyme conditions $\left(50^{\circ} \mathrm{C}, \mathrm{pH} 2.5\right)$. HPLC analyses, showed a single major peak for the sample containing only $\mathrm{CPyF}$ (control sample) at $35^{\circ} \mathrm{C}, \mathrm{pH} 7.0$ (Fig. 2a) as well as at $50{ }^{\circ} \mathrm{C}, \mathrm{pH} 2.5$ (Fig. 2c) and having a retention time of 3.62 min with a relative area of $97 \%$. On the other hand, for a PYT treated sample at $35^{\circ} \mathrm{C}, \mathrm{pH} 7.0$, multiple peaks were observed. Notably, it was observed that there was decrease in relative area by $72 \%$ at the retention time of CPyF (Fig. 2b). A similar study with PYT at $50{ }^{\circ} \mathrm{C}, \mathrm{pH}$ 2.5 , the relative peak area seen at retention time of $\mathrm{CPyF}$ showed an even higher decrease in relative area by $91 \%$
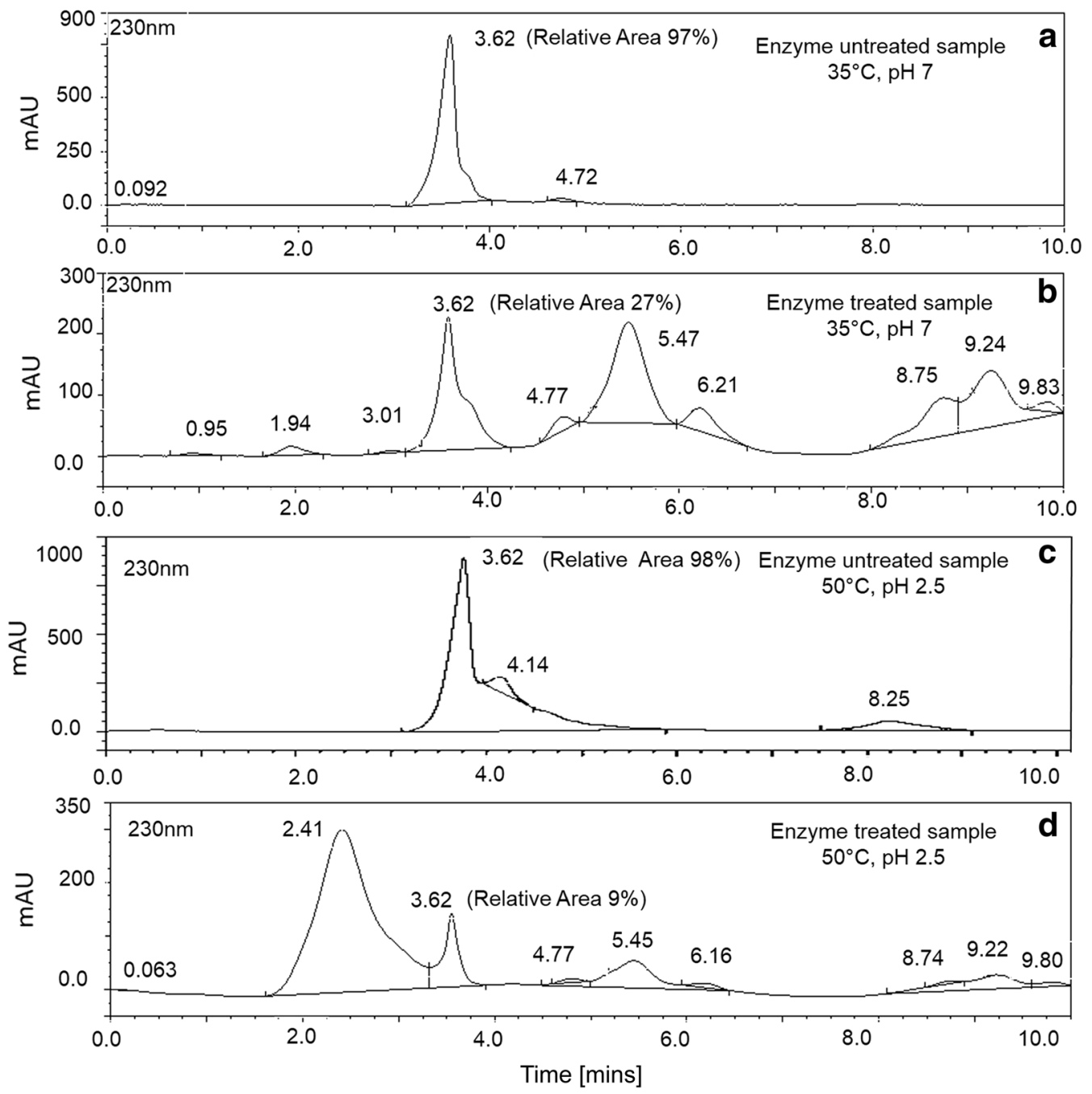

Fig. 2 Reduction of CPyF using phytase at different conditions $\mathbf{a}, \mathbf{c}$. CPyF before phytase action, $\mathbf{b}, \mathbf{d}$. CPyF after phytase action 
(Fig. 2d). The positive result for CPyF suggested degradation studies with other OpPs, namely, MCP and MP by PYT would be useful. HPLC analysis with MCP having a retention time of $5.5 \mathrm{~min}$ for the control sample (Additional file 1: Figure S4a) at $35{ }^{\circ} \mathrm{C}, \mathrm{pH} 7.0$ showed that a higher unit of PYT (250 IU) to obtain 53\% degradation in $4 \mathrm{~h}$ (Additional file 1: Figure S4b) when compared to CPyF (PYT 100 IU, 72\% degradation) (Fig. 2) in 2 h. Better degradation results with MP (HPLC retention time of $9.5 \mathrm{~min}$ for the control sample, Additional file 1: Figure S4c) in comparison with MCP were obtained by a higher decrease in peak area (77\%) on treatment with PYT (250 IU) (Additional file 1: Figure S4d) in $4 \mathrm{~h}$. Thus, all the above results with $\mathrm{CPyF}, \mathrm{MCP}$ and MP corroborate the finding that PYT has the ability to effectively act on OpP and degrade them.

\section{Application of PYT on harvested green chilli (Capsicum annuum $\mathrm{L}$ )}

Phytase shows dephosphorylation action by breaking the phospho-ester bond to release phosphate from substrate (Joshi 2014). As per food safety and standards authority of India (FSSAI), limit of $\mathrm{CPyF}$ on vegetables is $0.2 \mathrm{ppm}$ (FSSAI notification 2011). Detoxification of $\mathrm{CPyF}$ is achieved by cleaving the phospho-ester bond, generating TCP as the major product along with DETP (Chen et al. 2012; Hanley et al. 2000; Bicker et al. 2005), which are both water soluble. Human studies show that, both the metabolites are considered as urinary markers of $\mathrm{CPyF}$ exposure and are easily excreted through urine within $12 \mathrm{~h}$. Studies on rat show that, TCP and DETP are the predominant urinary metabolites of $\mathrm{CPyF}$ catabolism (Bicker et al. 2005). In the present study, the applicability of PYT applied on post-harvest chillies to degrade water insoluble $\mathrm{CPyF}$ was therefore studied with respect to the formation of TCP and DETP water soluble degradation products.

LC-MS analysis of standard CPyF showed that it eluted with a retention time (RT) of $5.56 \mathrm{~min}$ and $\mathrm{m} / z$ of 349.90 while DETP and TCP eluted at 0.72 and $3.48 \mathrm{~min}$ with $\mathrm{m} / z$ values of 169.17 and 198 , respectively. In PYT untreated sample (control), a single peak was detected after LC-MS analysis with a RT of $5.56 \mathrm{~min}$ and $\mathrm{m} / z$ of 349.90 indicating it to be CPyF (Fig. 3a). In PYT treated sample, 3 peaks (Fig. 3b-d) were observed at RT of 0.72 , 3.48 and $5.56 \mathrm{~min}$. MS analysis of these peaks showed $m / z$ values of $169.17,198$ and 349.90, respectively. On comparing with the standards, the 3 peaks were ascertained to be DETP, TCP and CPyF, respectively. The percent degradation of CPyF using PYT from $A$. niger NCIM 563 can vary depending on $\mathrm{pH}$ and temperature prevailing at the field. Peak area analysis shows $8 \%$ degradation of $\mathrm{CPyF}$ at $35^{\circ} \mathrm{C}$ and $\mathrm{pH} 7.0$ in $2 \mathrm{~h}$ using PYT (80 IU). To increase the degradation, higher units of phytase or reaction time may thus be required. On using higher units of PYT (250 IU) to degrade CPyF on green chilli our results in fact showed that $90 \%$ degradation was possible in $12 \mathrm{~h}$ (Additional file 1: Figure S5a, b). It is reported that TCP is not fetotoxic and teratoxic in either rat or rabbits at dosage levels of $100 \mathrm{ppm}$. TCP is shown to have moderate toxicity to salmonoids at $\mathrm{LD}_{50}$ value of $1.8 \mathrm{ppm}$ (Marino et al. 1999). Studies of TCP showed that a minimum concentration of $0.6 \mathrm{ppm}$ when exposed for $24 \mathrm{~h}$ is toxic during the multiple developmental stages of zebra fish (Suvarchala and Philip 2016). Our observation is that PYT can degrade CPyF present on raw agricultural products. Thus, development of a potential new way that prevents toxic OpP from entering the food chain by forming easily removable metabolites could become possible.

\section{Media optimization for enhanced PYT production in shake flask}

For the $12 \mathrm{PBD}$ runs the experimentally obtained maximum response values of PYT activity (IU/mL) obtained on the 6th day (i.e., $144 \mathrm{~h}$ ) are reported in Additional file 1: Table S3. Run number 10 showed a maximum PYT production value of $132 \pm 6.6 \mathrm{IU} / \mathrm{mL}$. Regression analysis of the response values obtained for the PBD runs yielded a best fit linear model, viz.,

$$
\begin{aligned}
\text { Phytase activity }= & 111.09-30.67 \times\left[\mathrm{NaNO}_{3}\right] \\
& +45.33 \times[\mathrm{GrCf}] \\
& -1644.44 \times\left[\mathrm{MnSO}_{4} \cdot \mathrm{H}_{2} \mathrm{O}\right] \\
& -190.0 \times\left[\mathrm{CaCl}_{2} \cdot 2 \mathrm{H}_{2} \mathrm{O}\right]
\end{aligned}
$$

The suitability of the model was further corroborated by ANOVA tests. Thus, the obtained model F-value of 11.35 implies the model is significant and that there is only a $0.35 \%$ chance that the model F-value could occur due to noise. The values of Prob > F was less than 0.05 , for the four variables showing their significance. The coefficient of determination $R^{2}=0.87$ provided a satisfactory measure for the variability in the observed response that could be explained by the model. The Pred $R^{2}$ of 0.61 is in reasonable agreement with Adj- $\mathrm{R}^{2}$ of 0.79 . The adeq precision, a measure of the signal-to-noise ratio, is found to have a high value of 9.72 and this indicated the signal strength to be strong. All the above tests confirm that the model Eq. (1) can be used to navigate the design space. In fact, using the above model, it was found that, the above four factors accounted for $86.68 \%$ of the total contribution to the estimates of the response values. The remaining variables then accounted for only $13.32 \%$ and thus PBD identified them to be less significant. The ANOVA results were complemented by the fact that four out of the 10 factors studied in the PBD, namely, $\mathrm{NaNO}_{3}, \mathrm{GrCf}, \mathrm{MnSO}_{4} \cdot \mathrm{H}_{2} \mathrm{O}$ 

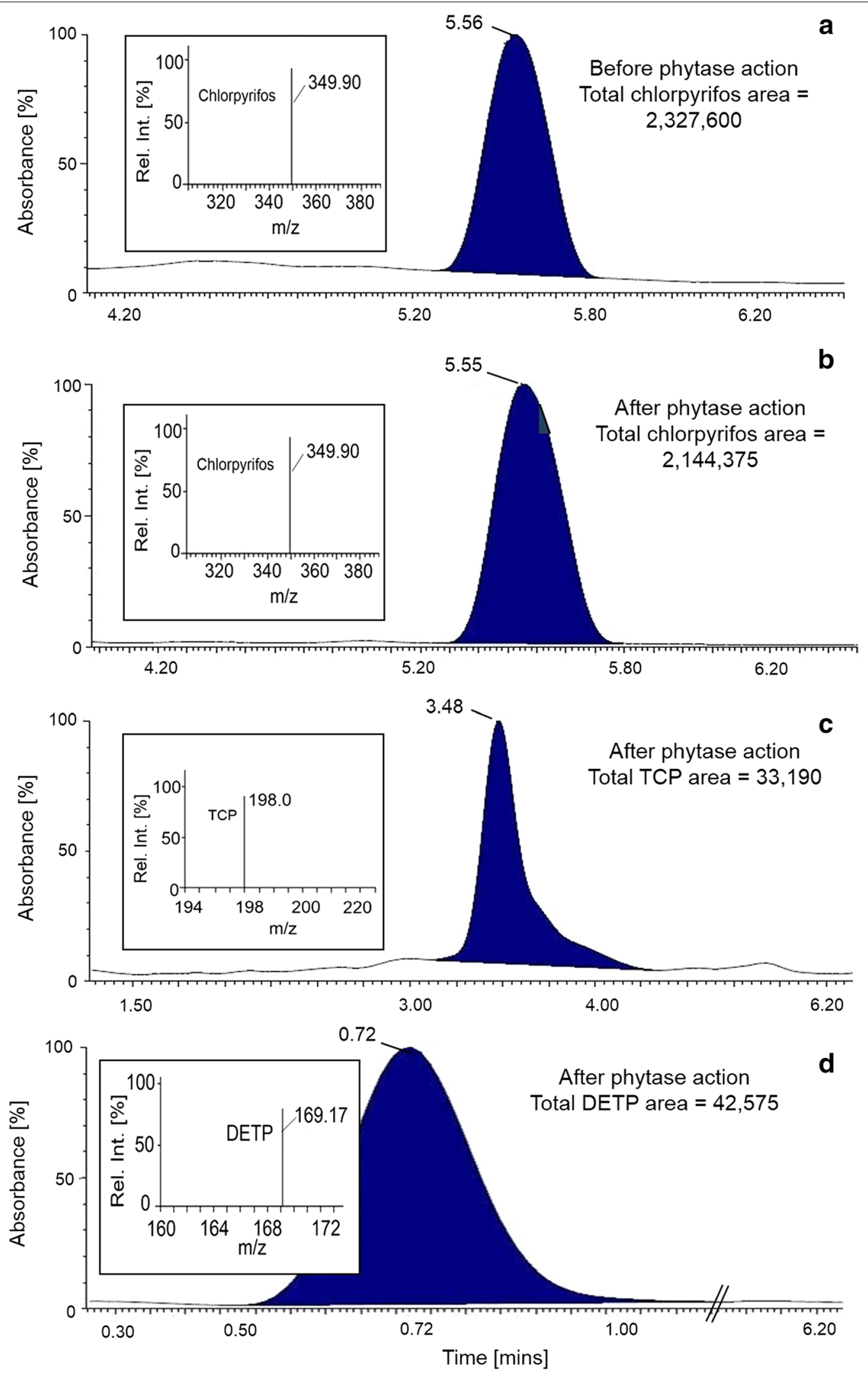

Fig. 3 Analysis of CPyF and its degraded metabolites using LC-MS. a CPyF on green chilli before phytase action. b CPyF on green chilli after phytase action. c Release of TCP after phytase action. d Release of DETP after phytase action 
and $\mathrm{CaCl}_{2} \cdot 2 \mathrm{H}_{2} \mathrm{O}$ were significant on comparing their t-values using a Pareto chart (Additional file 1: Figure S6).

The maximum contributory factors identified by $\mathrm{PBD}$ for PYT production were further optimized by a BBD of experiments (29 runs) generated by DES employing three chosen levels for each variable. Additional file 1: Table S4 gives the $\mathrm{BBD}$ for the four significant variables along with the experimentally obtained PYT activity. We observe that the optimization studies showed that run number 25 remarkably improved the PYT activity $(160 \pm 8.0 \mathrm{IU} /$ $\mathrm{mL}$ ). The wide variation in activity reported in all the runs bring out the process sensitivity to the experimentally chosen conditions and shows the usefulness of having carried out this systematic optimization study. The response data of BBD runs was regressed successfully using actual factors and interestingly showed linear dependency without interacting terms, namely,

Phytase activity $=286.74-49.17 \times\left[\mathrm{NaNO}_{3}\right]$

$$
-120.83 \times[\mathrm{GrCf}]
$$

The ANOVA analysis of the above model satisfied the statistical tests with an obtained model F-value of 27.95 implying that, the model is significant with only a $0.01 \%$ chance that the model F-value could arise due to noise. The value of correlation coefficient (Pred $R^{2}=0.62$ ) for PYT production suggested a good agreement between the observed and model predicted response values. The coefficient of determination $\left(\mathrm{R}^{2}=0.68\right)$, suggests that $68 \%$ of the variability in the data was explained by Eq. 2 . The obtained signal-to-noise ratio value of 15.04 brought out the presence of an adequate signal.

The final formulation of ten variables in the range studied in PBD and BBD showed that the highest activity of $160 \pm 8.0 \mathrm{IU} / \mathrm{mL}$ was obtained in $132 \mathrm{~h}$ with $100 \mathrm{~mL}$ media comprising of (g\%): 4.0 glucose; $0.4 \mathrm{NaNO}_{3} ; 0.075$ $\mathrm{MgSO}_{4} \cdot 7 \mathrm{H}_{2} \mathrm{O} ; 0.075 \mathrm{KCl} ; 0.015 \quad \mathrm{FeSO}_{4} \cdot 7 \mathrm{H}_{2} \mathrm{O} ; 0.015$ Tween 80; 1.0 GrCf; 0.35 dextrin; $0.02 \mathrm{MnSO}_{4} \cdot \mathrm{H}_{2} \mathrm{O}$ and $0.1 \mathrm{CaCl}_{2} \cdot 2 \mathrm{H}_{2} \mathrm{O}$. To validate the formulation, a time course experiment for PYT production was carried out using this optimized condition. The results obtained after showed that a 1.86 fold enhancement in PYT activity from $86 \pm 4.3 \mathrm{IU} / \mathrm{mL}$ to $160 \pm 8.0 \mathrm{IU} / \mathrm{mL}$ with glucose completely utilized in 5.5 days (i.e., $132 \mathrm{~h}$ ) was achieved by adopting the outlined hybrid media optimization approach (Fig. 4). The effect of varying the phosphate concentration by addition of sodium phytate and $\mathrm{KH}_{2} \mathrm{PO}_{4}$ using the optimized media formulation with $1 \% \mathrm{GrCf}$ was thus studied. Results showed that the PYT activity decreased to $79 \mathrm{IU} / \mathrm{mL}$ on addition of sodium phytate $(0.004 \mathrm{~g} \%)$ and to $151 \mathrm{IU} / \mathrm{mL}$ on addition of $\mathrm{KH}_{2} \mathrm{PO}_{4}(0.002 \mathrm{~g} \%)$. This may be compared to PYT activity of $160 \mathrm{IU} / \mathrm{mL}$ obtained using the optimized media with $1 \% \mathrm{GrCf}$ and suggests that it optimally provides the requirements of phosphate.

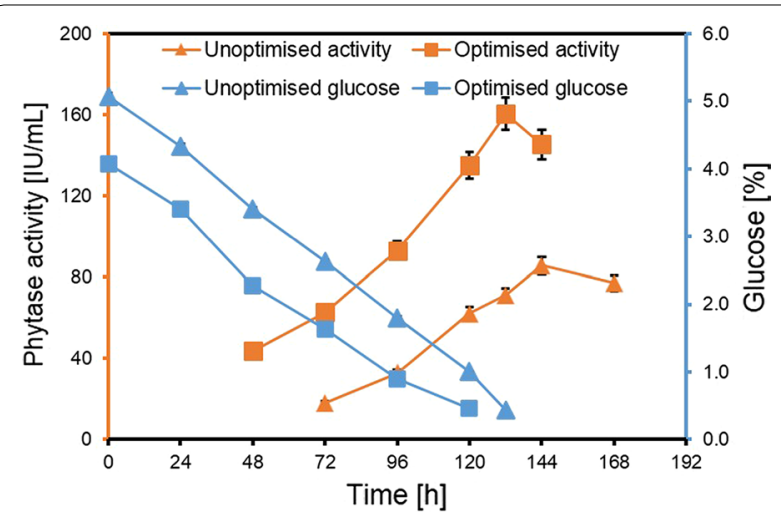

Fig. 4 Validation of phytase production by using unoptimized and optimized media. Experiments were carried out in triplicate (mean \pm SD)

\section{Scale-up studies of PYT production in batch fermenters}

The optimized media formulation was studied in scaledup larger volume batches using fermenters to ensure maintenance of the PYT production throughput. The results of fermentation studies carried out with 2 and 10-L media scaled-up volume batches are discussed below. It is expected that when operating with larger volumes, the dissolved oxygen (DO) is an important factor to consider and this would depend on both the aeration rate and the agitation speed. For the present studies, we chose to keep the aeration rate constant at $0.5 \mathrm{vvm}$ while varying the initial agitation speeds $(400,500,600 \mathrm{rpm})$. The behavior in time of DO and $\mathrm{pH}$ were simultaneously monitored. For the $400 \mathrm{rpm}$ run, a decrease in DO was observed till 36 h. 50\% DO was maintained by gradual increase in rpm and it was thus maintained at the higher $\mathrm{rpm}$. The $\mathrm{pH}$ of the media gradually decreased from 5.0 to 2.3. For the 2-L batch study with an initial rpm of 400 , the maximum activity of $97 \pm 4.8 \mathrm{IU} / \mathrm{mL}$ was obtained in $132 \mathrm{~h}$. PYT production of $122 \pm 6.1 \mathrm{IU} / \mathrm{mL}$ and $158 \pm 7.9 \mathrm{IU} / \mathrm{mL}$ was achieved at initial rpm of 500 and 600 respectively, in $132 \mathrm{~h}$. Thus, PYT production was successfully scaled up to 2 - $\mathrm{L}$ production from the shake flask experiment (158 $\pm 7.9 \mathrm{IU} / \mathrm{mL}$ at $600 \mathrm{rpm}$ ) (Fig. 5a).

Successful production at 2-L scale, paved way to studying the feasibility of enzyme production in a $10-\mathrm{L}$ volume fermenter to bring out the process biotech potential. Similar to studies in the 2-L scale and varying the initial agitation speed (400, 500 and $600 \mathrm{rpm}$ ), the $\mathrm{DO}$ and $\mathrm{pH}$ were monitored in $10-\mathrm{L}$ scale. $\mathrm{DO}$ and $\mathrm{pH}$ pattern were again observed, but with higher decreasing rates than in the 2-L scale. Remarkably, the maximum PYT activity of $164 \pm 8.2 \mathrm{IU} / \mathrm{mL}$ was maintained but it is important to note that the maximum activity was obtained in a much shorter time of $96 \mathrm{~h}$ at $500 \mathrm{rpm}$ (Fig. 5b). 

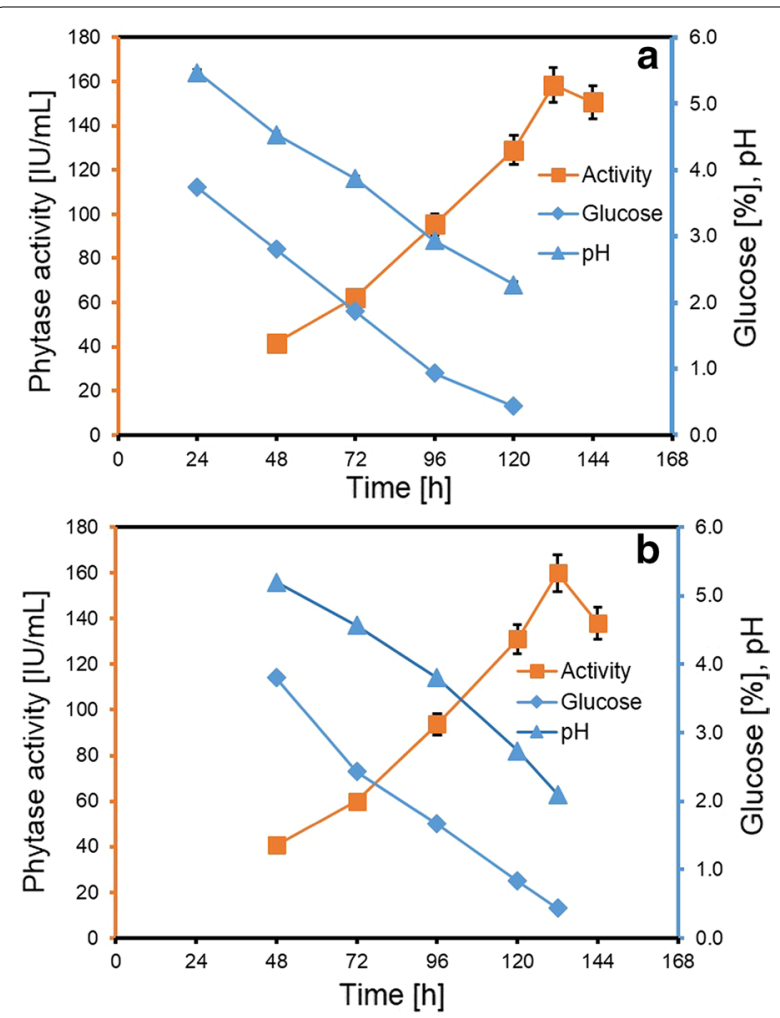

Fig. 5 Fermenter scale production a 2-L (at $600 \mathrm{rpm}$ ) and b 10-L (at 500 rpm) depicting phytase activity, $\mathrm{pH}$ and glucose concentration. Experiments were carried out in triplicate (mean \pm SD)

\section{Discussion}

Phytase is widely used to act on phytic acid for the aim of increasing the bioavailability of phosphorus, proteins and essential minerals in animal diets. It is commercially produced by employing a submerged fermentation process using spore inoculum (Coban and Demirci 2014; Krishna and Nokes 2001). We considered it desirable to carry out studies that use vegetative inoculum for PYT production over spore inoculum that is commonly employed for PYT production. Results obtained suggest that PYT production may in fact be enhanced using vegetative inoculum. This result is of considerable significance. Similar results of enhanced PYT production have been observed using vegetative inoculum in solid state fermentation (Krishna and Nokes 2001). Our studies also show that the use of $\mathrm{GrCf}$ as substrate for PYT production with A. niger NCIM 563 gives activity and productivity higher than earlier reports under submerged fermentation conditions using different strains and substrates (Table 1). Our observation is that the PYT produced using GrCf is active and highly stable over wide range of temperature and $\mathrm{pH}$ that simulates gastric conditions and brings out its superiority for use in animal feed applications. A novel application of PYT in degrading CPyF, MCP and MP is also discussed here to bring out its potential as an agent for pesticide degradation. It needs to be noted that FDA has approved $A$. niger as a generally-recognized-as-safe (GRAS) organism (Schuster et al. 2002). Together with the laboratory study and analysis report obtained from Central Avian Research Institute, Bareilly (UP), India confirms that $A$. niger NCIM 563 is a non-mycotoxin producer and the PYT obtained can thus be advantageously exploited.

Statistical experimentation for media optimization provides a time saving approach for enhancing PYT production (Bhavsar et al. 2013) and provides the base experimental conditions maintaining/improving the productivity for scale-up. Our results with this approach showed that the PYT productivity obtained in a $10-\mathrm{L}$ fermenter working volume $(41.0 \mathrm{IU} / \mathrm{mL} /$ day $)$ was improved by a factor of 2.87 and 1.41 times from shake flask $(14.3 \mathrm{IU} / \mathrm{mL} /$ day $)$ and $2-\mathrm{L}$ scale $(29 \mathrm{IU} / \mathrm{mL} /$ day $)$ experiments, respectively. The increase in productivity

Table 1 Comparing phytase productivity of A. niger NCIM 563 with other Aspergillus species

\begin{tabular}{|c|c|c|c|c|c|c|}
\hline Microbial strain & Media & $\begin{array}{l}\text { Optimum } \\
\mathrm{pH}\end{array}$ & $\begin{array}{l}\text { Optimum } \\
\text { temp }\left({ }^{\circ} \mathrm{C}\right)\end{array}$ & $\begin{array}{l}\text { PYT activity } \\
\text { (IU/mL) }\end{array}$ & $\begin{array}{l}\text { Productivity } \\
\text { (IU/mL/day) }\end{array}$ & Reference \\
\hline A. niger NCIM 563 & GrCfa (optimized) & 2.5 & 50 & 160.0 & 29.00 & Present work \\
\hline A. fumigatus NF 191 & PSM (optimized) & $(-)$ & $(-)$ & 101.79 & 25.40 & Gangoliya et al. (2015) \\
\hline $\begin{array}{l}\text { A. oryzae } \\
\text { SBS } 50\end{array}$ & Starch & 5.0 & 35 & 15.70 & 3.90 & Sapna (2013) \\
\hline A. niger CFR 335 & Potato dextrose broth & $(-)$ & $(-)$ & 9.60 & 1.92 & $\begin{array}{l}\text { Shivanna and } \\
\text { Venkateswaran (2014) }\end{array}$ \\
\hline A. ficuum SGA 01 & Potato dextrose broth & $(-)$ & $(-)$ & 8.20 & 1.64 & Howson and Davis (1983) \\
\hline A. ficuum NRRL 3135 & MRS medium & $(-)$ & $(-)$ & 2.27 & 0.45 & Howson and Davis (1983) \\
\hline $\begin{array}{l}\text { A. heteromorphus } \\
\text { MTCC } 10685\end{array}$ & $\begin{array}{l}\text { Phytase screening } \\
\text { medium (optimized) }\end{array}$ & 6.0 & 30 & 24.88 & 5.00 & Lata et al. (2013) \\
\hline
\end{tabular}

(-) No data reported

a GrCf-green chickpea flour 
with reduction in production time at $10-\mathrm{L}$ fermenter scale may be due to the better maintenance of fermentation parameters viz., agitation, temperature, aeration, etc. This observation further supports the biotech potential of the present PYT production process. Studies of submerged PYT production using $S$. thermophile in cane molasses medium showed that the productivity obtained in the $10-\mathrm{L}$ working volume fermenter $(5.2 \mathrm{IU} / \mathrm{mL} /$ day $)$ was improved by a factor of 2.2 times from shake flask (2.5 IU/ $\mathrm{mL} /$ day) experiments and having optimum activity at $\mathrm{pH}$ 5.5 and $45{ }^{\circ} \mathrm{C}$ (Singh and Satyanarayana 2008). Similar trend of increased productivity by 1.5 times for glucoamylase production was observed by Kumar et al. (2007).

In conclusion, the present study shows an efficient process of producing PYT, which has wide applications prospects in animal feed and agriculture. Our studies obtained high yields of PYT from A. niger NCIM 563 using GrCf. The PYT from $A$. niger was found to be stable over wide range of temperature and $\mathrm{pH}$ and has thus shown the necessary potential for use as animal feed supplement as well as on crops for field applications. The PYT from A. niger NCIM 563 beneficially shows biodegradation of $\mathrm{CPyF}$ when tested on green chillies. Studies show biodegradation of $\mathrm{CPyF}$ is maximum at conditions chosen close to the enzyme optimum conditions for high PYT activity $\left(50{ }^{\circ} \mathrm{C}\right.$ and $\left.\mathrm{pH} 2.5\right)$. These findings thus bring out an interesting and new applications for PYT produced from GrCf and A. niger NCIM 563. Although, the above optimal conditions do not correspond to field, they do justify the need to carry out studies that would improve the efficacy of PYT for biodegradation of OpP compounds.

\section{Additional files}

Additional file 1. Additional figures and tables.

Additional file 2. Additional data.

\section{Abbreviations}

BBD: Box-Behnken design; CPyF: chlorpyrifos; GrCf: green chickpea flour; MCP: monocrotophos; MP: methyl parathion; OpP: organophosphorus pesticide; PYT: phytase; PBD: Plackett-Burman design.

\section{Authors' contributions}

PS carried out the experiments. JM participated in the design of the study, supervised the research work and reviewed the manuscript. VR designed the statistical optimization studies, drafted and edited the original manuscript. SD supervised the research work, administered the project and funding. All authors have read and approved the final manuscript.

\section{Author details}

${ }^{1}$ Academy of Scientific and Innovative Research (AcSIR), Council of Scientific and Industrial Research-National Chemical Laboratory, CSIR-NCL, Pune 411008, India. ${ }^{2}$ National Collection of Industrial Micro-organisms (NCIM) Resource Center, Biochemical Sciences Division, CSIR-NCL, Pune 411008, India. ${ }^{3}$ Chemical Engineering and Process Development Division (CEPD), CSIR-NCL, Pune 411008, India.

\section{Acknowledgements}

PS would like to thank Council of Scientific and Industrial Research (CSIR) for Senior Research Fellowship. The authors thank Dr. Ameeta Ravikumar, Institute of Bioinformatics and Biotechnology (IBB), Savitribai Phule Pune University (SPPU) for scientific discussions on the pesticide degradation studies. We thank Maarc Labs Pvt. Ltd., Pune, recognized by the National Accreditation Board for Testing and Calibration, for carrying out the reported LCMS studies.

\section{Competing interests}

The authors declare that they have no competing interests.

\section{Availability of data and materials}

The datasets supporting the conclusions of this article are included within the article and its additional file.

\section{Funding}

The funding for the pesticide degradation analysis carried out at Maarc labs Pvt. Ltd., was provided by Department of Biotechnology (DBT) funded project (GAP 313226)

Received: 16 December 2016 Accepted: 13 March 2017

Published online: 21 March 2017

\section{References}

Alves NM, Guimarães LHS, Piccoli RH, Cardoso PG (2016) Production and partial characterization of an extracellular phytase produced by Muscodor sp. under submerged fermentation. Adv Microbiol 6:23-32

Baishya K, Sarma HP (2015) Advances in biodegradation of organophosphorus pesticides. Arch Appl Sci Res 7:37-43

Bhavsar K, Shah P, Soni SK, Khire JM (2008) Influence of pre-treatment of agriculture residues on phytase production by Aspergillus niger NCIM 563 under submerged fermentation conditions. Afr J Biotechnol 7:1101-1106

Bhavsar K, Gujar P, Shah P, Kumar VR, Khire JM (2013) Combinatorial approach of statistical optimization and mutagenesis for improved production of acidic phytase by Aspergillus niger NCIM 563 under submerged fermentation condition. Appl Microbiol Biotechnol 97:673-679

Bicker W, Lammerhofer M, Genser D, Kiss H, Lindner W (2005) A case study of acute human chlorpyrifos poisoning: novel aspects on metabolism and toxicokinetics derived from liquid chromatography-tandem mass spectrometry analysis of urine samples. Toxicol Lett 159:235-251

Boopathy R (2000) Factors limiting bioremediation technologies. Bioresour Technol 74:63-67

Box GE, Hunter WG, Hunter JS (1978) Statistics for experiments: an introduction to design data analysis and model building (Chapters 12, 13). Wiley, New York

Buddhiwant P, Bhavsar K, Ravi Kumar V, Khire J (2015) Phytase production by solid state fermentation of groundnut oil cake by Aspergillus niger: a bioprocess optimization study for animal feedstock applications. Prep Biochem Biotechnol. doi:10.1080/10826068.2015.1045606

Chen S, Liu C, Peng C, Liu H, Hu M, Zhong G (2012) Biodegradation of chlorpyrifos and its hydrolysis product 3,5,6-Trichloro-2-Pyridinol by a new fungal strain Cladosporium cladosporioides Hu-01. PLoS ONE 7:e47205

Chino-Flores C, Dantan-Gonzalez E, Vazquez-Ramos A, Tinoco-Valencia R, DíazMéndez R, Sánchez-Salinas E, Castrejón-Godínez ML, Ramos-Quintana F, Ortiz-Hernández ML (2012) Isolation of the opdE gene that encodes for a new hydrolase of Enterobacter sp. capable of degrading organophosphorus pesticides. Biodegradation 23:387-397

Christodoulou V, Bampidis VA, Hučko B, lliadis C, Mudř́k Z (2006) Nutritional value of chickpeas in rations of broiler chickens. ArchivGeflügelk 70:112-118

Coban H, Demirci A (2014) Enhanced submerged Aspergillus ficuum phytase production by implementation of fed-batch fermentation. Bioprocess Biosyst Eng 37:2579-2586

Debarati P, Gunjan P, Janmejay P, Rakesh VJK (2005) Accessing microbial diversity for bioremediation and environmental restoration. Trends Biotechnol 23:135-142 
Dersjant-Li Y, Awati A, Schulze H, Partridge G (2015) Phytase in non-ruminant animal nutrition: a critical review on phytase activities in the gastrointestinal tract and influencing factors. J Sci Food Agric 95:878-896

FSSAI notification (2011) http://www.fssai.gov.in/Portals/0/Pdf/Food\%20 safety\%20and\%20standards\%20(contaminants,\%20toxins\%20and\%20 residues)\%20regulation,\%202011.pdf

Gangoliya SS, Gupta RK, Singh NK (2015) Phytase production through response surface methodology and molecular characterization of Aspergillus fumigatus NF191. Indian J Exp Biol 53:350-355

Gao Y, Chen S, Hu M, Hu Q, Luo J, Li Y (2012) Purification and characterization of a novel chlorpyrifos hydrolase from Cladosporium cladosporioides Hu 01. PLOS ONE 7:e38137. doi:10.1371/journal.pone.0038137

Garsen A, Dotas D, Florou-Paneri P, Nikolakakis I (2007) Performance and egg quality traits of layers fed diets containing increasing levels of chickpea. Anim Sci Rev 36:3-14

Hanley T Jr., Carney E, Johnson E Jr (2000) Developmental toxicity studies in rats and rabbits with 3,5,6-Trichloro-2-pyridinol, the major metabolite of chlorpyrifos. Toxicol Sci 53:100-108

Heinohen JK, Lathi RJ (1981) A new and convenient colorimetric determination of inorganic orthophosphate and its application to the assay of inorganic pyrophosphatase. Anal Biochem 113:313-317

Howson SJ, Davis RP (1983) Production of phytate-hydrolyzing enzyme by some fungi. Enzyme Microb Technol 5:377-382

John EM, Shaike JM (2015) Chlorpyrifos: pollution and remediation. Environ Chem Lett 13:269-291

Joshi JB (2014) Phytase: a key to unlock phytate complex. Int J Pure Appl Biosci 2:304-313

Khuri Al, Cornell JA (1987) Response surfaces: design and analysis. Marcel Decker Inc., New York. ISBN 0-824-77653-4

Krishna C, Nokes SE (2001) Predicting vegetative inoculum performance to maximize phytase production in solid-state fermentation using response surface methodology. J Ind Microbiol Biotechnol 26:161-170

Kumar S, Kumar P, Satyanarayana T (2007) Production of raw starch-saccharifying thermostable and neutral glucoamylase by the thermophilic mold Thermomucor indicae-seudaticae in submerged fermentation. Appl Biochem Biotechnol 142:221-230

Kumar V, Sinha A, Makkar H, Becker K (2010) Dietary roles of phytate and phytase in human nutrition: a review. Food Chem 120:945-959

Lata S, Rastogi S, Kapoor A, Imran M (2013) Optimization of culture conditions for the production of phytase from Aspergillus heteromorphus MTCC 10685. Int J Adv Biotechnol Res 4:224-235

Lei X, Stahl CH (2001) Biotechnological development of effective phytases for mineral nutrition and environmental protection. Appl Microbiol Biotechnol 57:474-481

Lowry OH, Rosebrough NJ, Farr AL, Randall RJ (1951) Protein measurement with the folin phenol reagent. J Biol Chem 193:265-275

Marino T, Gilles M, Rick D, Henry K (1999) Evaluation of the toxicity of 3, 5, 6-trichloro-2-pyridinol (TCP) to the early life stages of the rainbow trout, Oncorhynchus mykiss Walbaum. Lab Project Number: 991173. Unpublished study prepared by The Dow Chemical Co. 56p
Mileson BE, Chambers JE, Chen WL, Dettbarn W, Enrich M, Eldefrawi AT, Gaylor DW, Hamernik K, Hodgson E, Karczmar AG, Padilla S, Pope CN, Richardson RJ, Saunders DR, Sheets LP, Sultatos LG, Wallace KB (1998) Common mechanism of toxicity: a case study of organophosphorus pesticides. Toxicol Sci 41:8-20

Miller GL (1959) Use of dinitrosalicylic acid reagent for determination of reducing sugar. Anal Chem 31:427-431

Plackett RL, Burman JP (1956) The design of optimum multifactor experiments. Biometrika 33:305-325

Rani R, Kumar S, Ghosh S (2014) Optimization of aqueous extraction process to enhance the production of phytase by Rhizopus oryzae using response surface methodology coupled with artificial neural network. Afr J Biotechnol 13:874-883

Rayu S, Karpouzas DG, Singh BK (2012) Emerging technologies in bioremediation: constraints and opportunities. Biodegradation 23:917-926

Sapna Singh B (2013) Improved production of protease-resistant phytase by Aspergillus oryzae and its applicability in the hydrolysis of insoluble phytates. J Ind Microbiol Biotechnol 40:891-899

Schuster E, Colemann N, Frisvad J, Dijck P (2002) On the safety of Aspergillus niger-a review. Appl Microbiol Biotechnol 59:426-435

Scott C, Begley C, Taylor MJ, Pandey G, Momiroski V, French N, Brearley C, Kotsonis S, Selleck M, Carino F, Bajet C, Clarke C, Oakeshott J, Russell R (2011) Free enzyme bioremediation of pesticides. ACS symposium series book 1075:155-174

Shah P, Bhavsar K, Soni SK, Khire JM (2009) Strain improvement and up scaling of phytase production by Aspergillus niger NCIM 563 under submerged fermentation conditions. J Ind Microbiol Biotechnol 36:373-380

Shivanna GB, Venkateswaran G (2014) Phytase production by Aspergillus niger CFR 335 and Aspergillus ficuum SGA 01 through submerged and solidstate fermentation. Sci World J. doi:10.1155/2014/392615

Singh B, Satyanarayana T (2008) Phytase production by Sporotrichum thermophile in a cost-effective cane molasses medium in submerged fermentation and its application in bread. J Appl Microbiol 105:1858-1865

Sutherland TD, Horne I, Weir KM, Coppin CW, Williams MR, Selleck M, Russell RJ, Oakeshott JG (2004) Enzymatic bioremediation: from enzyme discovery to applications. Clin Exp Pharmacol Physiol 31:817-821

Suvarchala G, Philip GH (2016) Toxicity of 3, 5, 6-trichloro-2-pyridinol tested at multiple stages of zebra fish (Danio rerio) development. Environ Sci Pollut Res. doi:10.1007/s11356-016-6684-3

Theriot CM, Grunden AM (2011) Hydrolysis of organophosphorus compounds by microbial enzymes. Appl Microbiol Biotechnol 89:35-43

Torres-Fuentes C, Alaiz M, Vioque J (2011) Affinity purification and characterization of chelating peptides from chickpea protein hydrolysates. Food Chem 129:485-490

Vendan SE (2016) Current scenario of biopesticides and eco-friendly insect pest management in India. South Ind J Biol Sci 2:268-271

Wyss M, Brugger R, Kronenberger A, Rémy R, Fimbel R, Oesterhelt G, Lehmann M, Loon A (1999) Biochemical characterization of fungal phytases (myoinositol hexakisphosphate phosphohydrolases): catalytic properties. Appl Environ Microbiol 65:367-373

\section{Submit your manuscript to a SpringerOpen ${ }^{\odot}$ journal and benefit from:}

- Convenient online submission

- Rigorous peer review

- Immediate publication on acceptance

- Open access: articles freely available online

- High visibility within the field

- Retaining the copyright to your article

Submit your next manuscript at springeropen.com 